\title{
Pseudomyxoma Peritonei and Ovarian Mucinous Borderline Tumor
}

\author{
Baquedano L*, Lanzón A, Bolea R, José Y and Ruiz-Conde MA \\ Gynecology Department, Hospital Universitario Miguel Servet, Zaragoza, Spain
}

Received: 㭗 September 9, 2018; Published: 制 September 14, 2018

*Corresponding author: Laura Baquedano Mainar, Ginecology Department, Hospital Universitario Miguel Servet, Zaragoza, Spain

\begin{abstract}
Pseudomyxoma peritonei is only rarely seen in conjunction with primary ovarian tumors. We describe a case of a late recurrence of a mucinous intestinal-type borderline ovarian tumor with disseminated peritoneal adenomucinosis.
\end{abstract}

Keywords: Borderline Ovarian Tumor; Low Malignant Potential; Borderline Ovarian Tumor Mucinous; Pseudomyxoma Peritonei

\section{Introduction}

Pseudomyxoma peritonei (PMP) is a rare entity with an incidence of 2 per million individuals per year [1]. It is slowly progressive mucinous malignant disease confined to the peritoneal cavity, usually originating from the appendix [2]. The predisposed areas within the peritoneal cavity of PMP are defined by fluid absorption through lymphatic lacunae and lymphoid aggregates (greater omentum, right hemidiaphragm) and gravity (pelvic cavity, paracolic gutters) [3] The natural course of the disease is slow progression of peritoneal mucinous masses until death caused by complications due to the bulk of tumor.

\section{Case Report}

A 36-year old woman without comorbidities who underwent unilateral adnexectomy and appendectomy in 2011 with diagnosis of low grade ovarian intestinal type borderline mucinous tumor. CA19.9 tumor marker testing was slightly elevated, $78 \mathrm{U} / \mathrm{ml}$; the others tumor markers were normal. Surgical exploration by median laparotomy showed widespread gelatinous mucinous ascites and a huge ruptured right ovarian tumor of $30 \mathrm{~cm}$ in diameter. All visible mucinous deposits were resected. The Immunohistochemistry study was: Ck7: +, Ck20: +++, CDX2: +, R.E: (-), R.P: (-), CEA: +, Muc2: +, Ki-67: + 5\%. No adjuvant therapy was given. In 2013 she had a pregnancy by in vitro fertilization with cesarean delivery and no evidence of tumor recurrence at that time. In 2017 the patient wanted a new pregnancy. Due to the diagnosis of early ovarian failure, she was remitted to the Reproduction Unit again. During the ovarian stimulation, a large column of fluid was observed through sonographic exploration in the douglas space. The Ca19.9 tumor marker testing was elevated again, $80 \mathrm{U} / \mathrm{ml}$. In the CT- scan there were signs of peritoneal carcinomatosis, so a diagnostic laparoscopy was performed showing a gelatinous-mucinous ascites and disseminated peritoneal carcinomatosis with implants widespread on the peritoneum, small intestine, colon, diaphragm and liver (Figures $1 \& 2$ ). A complete surgical debulking was judged to be technically impossible. Anatomopathological examination showed multiple deposits of mucus without visible tumor epithelial cells and some mucinous cells intestinal type in biopsied peritoneal implants with very mild atypia. Postoperatively no major wound complication occurred and 4 weeks after surgery, the woman was sent to Oncology to assess starting chemotherapy treatment.

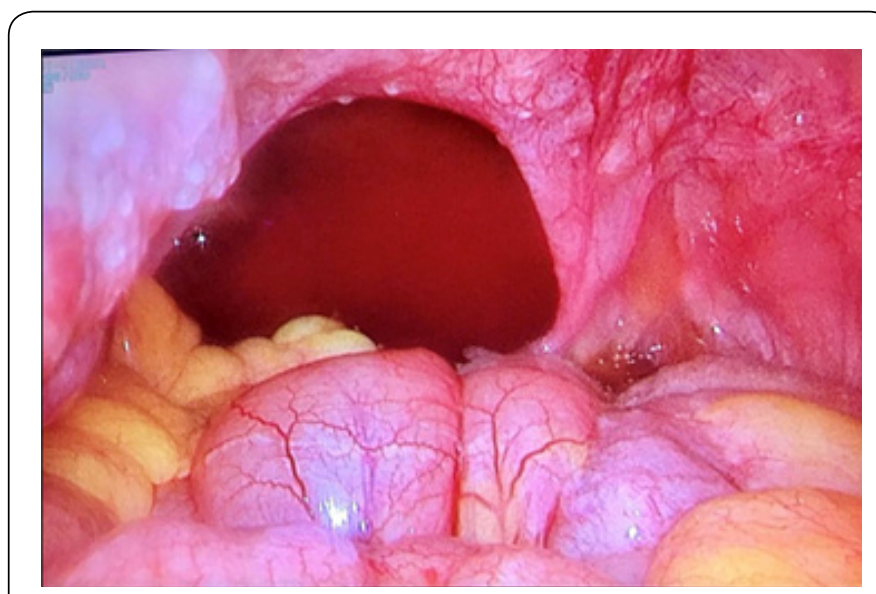

Figure 1. 


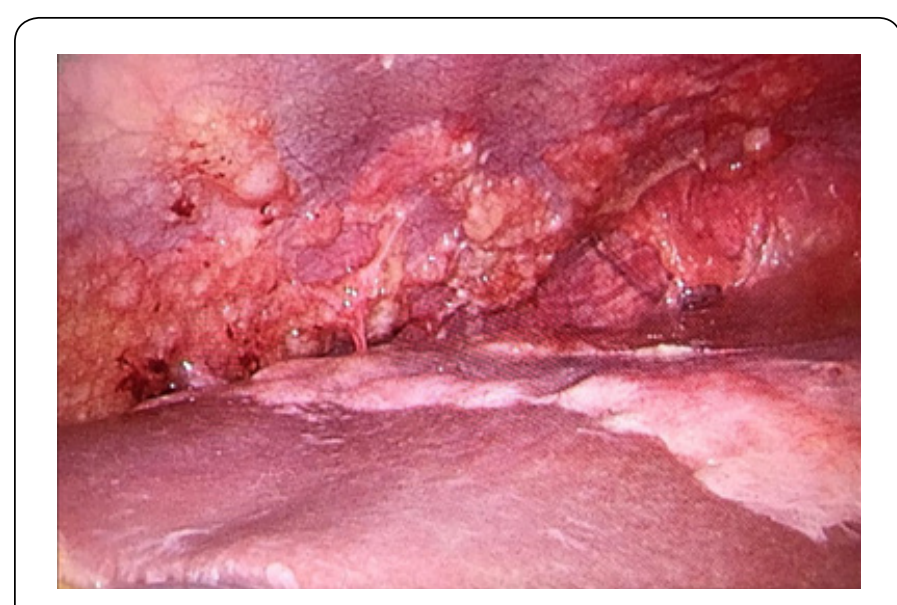

Figure 2.

\section{Discussion}

$10 \%$ of ovarianepithelial tumors consist of mucinous tumors. The vast majority of mucinous tumors are benign (75\%), 10\% borderline and 15\% invasive carcinomas [4]. Three histopathological groups of mucinous tumors have been described: mucinous cystadenoma mucinous tumor of uncertain malignant potential (borderline) and invasive mucinous carcinoma [5]. Mucinous borderline tumors produce large multicystic masses with smooth outer surfaces that may resemble benign mucinous cystadenomas. PMP is defined clinically on the basis of intraoperative findings as a grossly visible, localized, or generalized accumulation of mucus in the pelvis or abdomen, either lying on and attached to the peritoneal surfaces or incorporated within dense fibrous tissue. The main causes are the appendicular origin (mucocele appendicular; 30\%). The most frequent cause of PMP originating from a primary ovarian tumor are the ruptured mucinous tumors arising in ovarian mature cystic teratomas and mucinous ovarian carcinoma $[4,6]$. Dissemination initially is locoregional, but, it is frequent to see multiple sites of localization [7]. There are no specific signs or pathognomonic tumor markers and the main sign is abdominal pain and ascite. A good washing of the peritoneal cavity is useful, but the recurrence is very frequent. The approach depends on the size of the lesions and damage. The natural course of the disease is slow progression of peritoneal mucinous masses until death caused by complications due to the bulk of tumor [8]. Intraoperative chemotherapy $[9,10]$ significantly improve the prognosis but his kind of treatment remains difficult and needs a specialized center. In our case, the clinical and immunohistochemical findings are consistent with a mucinous borderline ovarian tumor associated with PMP 7 years after the surgery. Usually recurrences of borderline tumors are treated by surgical debulking. In the present case secondary debulking was technically not achievable, hence our decisión to start with chemotherapy treatment.

\section{Conclusion}

Even though the recurrence risk of mucinous borderline ovarian tumors is low, a careful follow-up, especially when a conservative surgical approach is selected is essential in these patients.

\section{References}

1. Smeenk RM, van Velthuysen ML, Verwaal VJ, Zoetmulder FA. (2008) Appendiceal neoplasms and pseudomyxoma peritonei: a populationbased study. Eur J Surg Oncol 34(2): 196-201.

2. Carr NJ, Cecil TD, Mohamed F, Sobin LH, Sugarbaker PH, et al. (2016) A consensus for classification and pathologic reporting of pseudomyxoma peritonei and associated appendiceal neoplasia: the results of the peritoneal surface oncology group international (PSOGI) modified Delphi process. Am J Surg Pathol 40(1): 14-26.

3. Sugarbaker PH (1994) Pseudomyxoma peritonei. A cancer whose biology is characterized by a redistribution phenomenon. Ann Surg 219(2): 109-11.

4. Hart WR (2005) Borderline epithelial tumors of the ovary. Modern Pathology 18: S33-50.

5. Hart WR (2005) Mucinous tumors of the ovary: a review. Int J Gynecol Pathol 24(1): 4-25.

6. Lee KR, Scully RE (2000) Mucinous tumors of the ovary: a clinicopathologic study of 196 borderline tumors (of intestinal type) and carcinomas, including an evaluation of 11 cases with 'pseudomyxoma peritonei'. Am J Surg Path 24(11): 1447-1464.

7. Fairise A, Barbary C, Derelle AL, Tissier S, Granger P, et al. (2008) Mucocele of the appendix and pseudomyxoma peritonei. Journal de radiologie 89:751-62.

8. Dayal S, Taflampas P, Riss S, Chandrakumaran K, Cecil TD, et al. (2013) Complete cytoreduction for pseudomyxoma peritonei is optimal but maximal tumor debulking may be beneficial in patients in whom complete tumor removal cannot be achieved. Dis Colon Rectum 56(12): 1366-1372.

9. Rizvi SA, Syed W, Shergill R (2018) Approach to pseudomyxoma peritonei. World J Gastrointest Surg 10(5): 49-56.

10. Mittal R, Chandramohan A, Moran B (2017) Pseudomyxoma peritonei: natural history and treatment. Int J Hyperthermia 33(5): 511-519. 
(C) (P) This work is licensed under Creative

To Submit Your Article Click Here: Submit Article

DOI: 10.32474/IGWHC.2018.02.000142

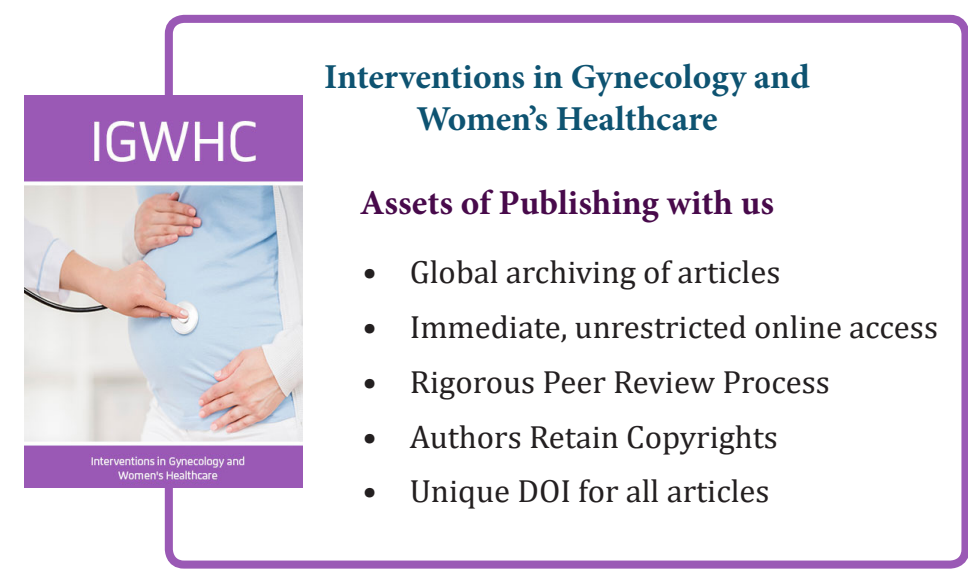

